\title{
Contribuição dos contos de fadas para o desenvolvimento Psicossocial infantil
}

\section{Contribution of fairy tales to child psychosocial development}

\section{Raisa Porto de Figueiredo ${ }^{1}$, Roberta Barbosa da Silva ${ }^{2}$}

Como citar esse artigo. FIGUEIREDO, R.P.; DA SILVA, R.B. Contribuição dos contos de fadas para o desenvolvimento Psicossocial infantil. Revista Mosaico, v.12, n.1, p. 48-52, 2021.

Nota da Editora. Os artigos publicados na Revista Mosaico são de responsabilidade de seus autores. As informações neles contidas, bem como as opiniões emitidas, não representam pontos de vista da Universidade de Vassouras ou de suas Revistas.

\section{Resumo}

Presentes na infância, os contos de fadas abordam experiências cotidianas, permitindo que as crianças se identifiquem com as dificuldades ou alegrias de seus personagens, desempenhando um papel fundamental no seu desenvolvimento. Nessa perspectiva, este artigo objetivou abordar sobre a importância dos contos de fadas no desenvolvimento psicossocial infantil. Para tal, realizou-se uma revisão da literatura quanto a história e estrutura dos contos de fadas, o desenvolvimento psicossocial infantil e as contribuições dos contos de fadas nesse aspecto. Por fim, notou-se o aporte dessa literatura no autoconhecimento, personalidade, entendimento das emoções e da sociedade em que está inserido e no reconhecimento dos conflitos e dilemas, contribuindo, assim, para o seu desenvolvimento psicossocial.

Palavras-chave: Contos de Fadas. Desenvolvimento psicossocial. Infância.

\begin{abstract}
Present in childhood, fairy tales address everyday experiences, allowing children to identify with the difficulties or joys of their characters, playing a fundamental role in their development. In this perspective, this article aimed to address the importance of fairy tales in child psychosocial development. To this end, a literature review was conducted regarding the history and structure of fairy tales, child psychosocial development and the contributions of fairy tales in this aspect. Finally, it was noted the contribution of this literature to self-knowledge, personality, understanding of emotions and the society in which it is inserted, the recognition of conflicts and dilemmas, thus contributing to their psychosocial development.

Keywords: Fairy tales. Psychosocial development. Childhood.
\end{abstract}

\section{Introdução}

Desde os tempos mais remotos os contos de fadas estão presentes na infância e exercem um grande fascínio nas crianças, afinal são histórias que estimulam a imaginação, transmitem conhecimento e valores culturais, além de abordar sentimentos comuns, como inveja, ódio, rejeição e abandono.

Esse tipo de literatura funciona como instrumento para a descoberta dos sentimentos da criança e causam impacto no psiquismo, pois tratam das experiências cotidianas, permitindo que elas se identifiquem com as dificuldades ou alegrias de seus heróis. Assim, a fantasia é fundamental para o desenvolvimento da criança, visto que, nessas histórias, ela se identifica mais facilmente com os problemas dos personagens e dão vazão às próprias emoções. (RESSURREIÇÃO, 2005).

Neste contexto, observa-se que os contos de fadas demonstram conflitos e relações vivenciadas pela criança na escola, em casa, com a família, amigos e entre outros, auxiliando na compreensão do mundo por meio da experiência dos personagens e pode influenciar no desenvolvimento infantil o que torna relevante tal estudo.

Diante disso, este artigo teve como objetivo geral abordar a importância dos contos de fada no desenvolvimento psicossocial infantil. Ademais, apresenta como objetivos específicos: caracterizar o desenvolvimento infantil, compreender as histórias dos contos de fadas e apontar as influências e importância dessa literatura no desenvolvimento infantil.

Esta pesquisa constitui-se em uma revisão de literatura a respeito dos contos de fadas, do

Afiliação dos autores:

1Graduanda, Curso de Psicologia, Universidade de Vassouras, Vassouras, RJ, Brasil

2Mestre em Psicologia, Professora Assistente III, Curso de Psicologia, Universidade de Vassouras, Vassouras, RJ, Brasil

*Email de correspondência: raiisa.porto@hotmail.com 
desenvolvimento psicossocial com abordagem na teoria desenvolvida por Erikson (1968, apud PAPALIA et al., 2001) e a contribuição desta literatura para o desenvolvimento infantil, sendo utilizados artigos publicados em revistas científicas, livros e trabalhos de conclusão de curso.

Estruturou-se este artigo da seguinte forma: a história e estrutura dos contos de fadas, o desenvolvimento psicossocial infantil, as contribuições dos contos de fadas no desenvolvimento infantil e, por fim, as considerações finais

\section{Os Contos de Fadas}

Os contos de fadas estão atrelados à infância, assim, faz-se necessário apresentar aqui sua concepção. Ariès (1978) afirma que até o século XII, não havia lugar para infância, uma vez que não era representada na arte medieval, e apenas no século XIII iniciou a sua descoberta. Porém, os sinais de seu desenvolvimento tornaram-se numerosos e significativos apenas no final do século XVI e durante o século XVII, quando ocorreram mudanças nos costumes, como a escolarização de crianças, trajes e nova visão de família.

Assim, segundo Azevedo (1999), a Literatura Infantil surge a partir do século XVII, pois antes desse período as crianças eram vistas como adultos em miniatura e participavam da vida adulta e, desta forma, não existiam histórias e livros específicos para essa fase e a literatura veiculada para crianças e adultos era exatamente a mesma.

Quanto aos contos de fadas, é praticamente impossível datar sua origem, visto que evidências históricas indicam que já havia referências a eles desde tempos remotos. A investigação sobre formas de difusão e transmissão dessas histórias é frequentemente revisitada, entretanto parece convergir que os contos se originaram entre os povos celtas (século II a.C.), que se estabeleceram principalmente na Gália, nas Ilhas Buta Nênias e na Irlanda, sendo posteriormente disseminados entre inúmeros povos, como os Persas, os Hindus, os Gregos e os Judeus (KUPSTAS, 1993; CAVALCANTI, 2002; SCHNEIDER et al., 2009).

Segundo Coelho (2003, apud FALCONI et al, 2015), os contos de fadas surgiram através da tradição oral, ou seja, testemunhos transmitidos verbalmente de uma geração à outra, porém, foram concretizados a partir da descoberta da infância, passando a ser contados de forma lúdica para crianças, pois originalmente eram construídos para o universo adulto.

[...] Somente no final do século XVII e durante o século XVIII, os primeiros livros infantis foram produzidos. A fantasia de criança, a imaginação a criatividade e o encantamento começaram a ganhar corpo de uma forma mais sutil. Isso se deu graças ao surgimento da Idade Moderna, foi quando se começou a entender que as necessidades das crianças são diferentes dos adultos, surgiu uma nova noção de família, houve uma reorganização escolar que junto com a pedagogia trabalharam no desenvolvimento da criança no que se diz respeito ao intelecto e emoção. (SILVA, 2013, p. 15-16).

Perrault e os irmãos Jacob e Wilheelm Grimm foram fundamentais para consolidar esse gênero. $\mathrm{O}$ francês Charles Perrault é considerado por muitos o primeiro autor a escrever obras infantis e organizar contos de fadas em livro, no século XVII. Adequou contos populares contados de boca a boca ao gosto da corte francesa, suprimindo questões referentes à violência e sexualidade, além de mencionar a "moral da história" ao final da narrativa com a intenção de moralizar e instruir ensinamento ao indivíduo. Ao coletar histórias populares, Perrault publicou versões imortais como A Bela Adormecida, A Gata Borralheira, Barba Azul, As Fadas, Pele de Asno, dentre outras. (NASCIMENTO et al., 2011; FALCONI et al., 2015).

Os irmãos Grimm, também, escreveram suas versões sobre os contos de fadas, no século XIX, surgindo à preocupação linguística com o contexto e objetivando preservar o patrimônio literário do povo alemão, sendo um acervo para todos. Destacam-se os contos que foram traduzidos para o português: A Bela Adormecida, Os Músicos de Bremen, Os Sete Anões e a Branca de Neve, Chapeuzinho Vermelho, O Corvo, As Aventuras do Irmão Folgazão, A Dama e o Leão. (FALCONI et al., 2015).

\section{[...]Oenredobásicodos contos defadas expressaosobstáculos, ou provas, que deveriam ser vencidas, para que o herói alcance sua autorrealização existencial, seja pelo encontro de seu verdadeiro eu, seja pelo encontro da princesa, que encarna o ideal a ser alcançado. (NASCIMENTO et al., 2011, p. 16427)}

Cashdan (2000, p. 25 apud PEREIRA et al., 2013) conceitua os contos de fadas como dramas sérios que refletem eventos que acontecem no interior da criança, assim, ajudam as crianças a lidar com as lutas internas que são parte de sua vida diária e, por este motivo, os contos de fadas não morrem.

Essas obras são consideradas um patrimônio da humanidade, porém, muitos clássicos infantis foram se modificando de acordo com a cultura e a época, havendo muita diferença dos originais para os atuais. A tendência atual é retirar o mal, o medo e o castigo de certas narrativas, além de apaziguar as emoções que precisam ser vividas. (NASCIMENTO et al., 2011)

\section{Desenvolvimento Psicossocial Infantil}

Inicialmente, apresenta-se como conceito para o desenvolvimento humano:

\footnotetext{
“O desenvolvimento humano é um processo de construção
} 
contínua que se estende ao longo da vida, sendo fruto de uma organização complexa e hierarquizada que envolve desde os componentes intraorgânicos até as relações sociais e a agência humana." (SIFUENTES et al., 2007, p. 379).

Papalia et al. (2001) categorizam o desenvolvimento em três domínios: físico-motor, cognitivo e psicossocial. Neste artigo, a ênfase será o desenvolvimento psicossocial infantil, abordando a Teoria Psicossocial elaborada em 1968, por Erikson, importante psicanalista. Essa teoria destaca-se pela inserção do estudo do homem no plano das relações psicossociais.

Erikson (1968, apud PAPALIA et al., 2001) afirma que o desenvolvimento psicossocial, compreende o processo do desenvolvimento do eu, influenciado socialmente e culturalmente e envolve a integração do desenvolvimento psicológico com a formação de relações sociais. Assim, pode-se compreender que as emoções, a personalidade e as relações sociais são aspectos do desenvolvimento psicossocial.

O desenvolvimento psicossocial é um processo contínuo que ocorre ao longo da vida, assim, cada parte do ciclo de vida apresenta suas características. Para Erikson (1968, apud PAPALIA et al., 2001) esse desenvolvimento se dá oito em períodos, conforme apresentado no quadro a seguir:

Para este artigo, serão enfatizados apenas o terceiro e quarto períodos, que comporta aproximadamente de 03 a 12 anos, visto que, de acordo com Dohme (2011), nessa faixa etária ocorre o interesse por enredos presentes nos Contos de Fadas, como personagens crianças ou animais, histórias ligadas à realidade, fantasias e aventuras.

Segundo essa teoria psicossocial de Erikson, entre 3 e 6 anos a criança está vivenciando a fase iniciativa versus culpa, sendo um período de maior organização física e mental.

O terceiro estágio psicossocial da vida, correspondente ao estágio psicossexual genital-locomotor, é o da iniciativa, uma época de crescente maestria e responsabilidade. A criança, nesse estágio, apresenta-se como claramente mais avançada e mais "organizada", tanto física quanto mentalmente. A iniciativa se combina com a autonomia para fazer com que ela seja ativa, determinada e capaz de planejar suas tarefas e metas. O perigo desse estágio é o sentimento de culpa que pode obcecar a criança por uma busca muito entusiasmada de metas, incluindo fantasias genitais e o uso de meios agressivos e manipulativos para chegar a essas metas. A criança está ansiosa para aprender e aprende bem nessa idade; ela desenvolve seu senso de obrigação e de desempenho. (HALL et al., 2007, p. 171-172).

O período de diligência versus inferioridade

Quadro 1. Estágios de desenvolvimento da Teoria Psicossocial.

\begin{tabular}{|c|c|c|}
\hline Período & $\begin{array}{l}\text { Qualidade de Ego a } \\
\text { ser desenvolvida }\end{array}$ & Algumas tarefas e atividades do estágio \\
\hline $\begin{array}{l}\text { Nascimento } \\
\text { aos } 12-18 \\
\text { meses }\end{array}$ & $\begin{array}{c}\text { Confiança básica } \\
\text { versus } \text { Desconfiança } \\
\text { básica }\end{array}$ & $\begin{array}{l}\text { O bebê desenvolve o senso de perceber se o } \\
\text { mundo é um lugar bom e seguro. }\end{array}$ \\
\hline $\begin{array}{c}12-18 \text { meses } \\
\text { aos } 3 \text { anos }\end{array}$ & $\begin{array}{l}\text { Autonomia versus } \\
\text { vergonha, dúvida. }\end{array}$ & $\begin{array}{l}\text { A criança desenvolve um equilibrio de } \\
\text { independência e autossuficiência em relação } \\
\text { à vergonha e à dúvida }\end{array}$ \\
\hline 3 aos 6 anos & $\begin{array}{l}\text { Iniciativa versus } \\
\text { Culpa }\end{array}$ & $\begin{array}{l}\text { A criança desenvolve a iniciativa quando } \\
\text { experimenta novas atividades e não é } \\
\text { dominada pela culpa. }\end{array}$ \\
\hline $\begin{array}{l}6 \text { anos à } \\
\text { puberdade }\end{array}$ & $\begin{array}{l}\text { Diligência versus } \\
\text { Inferioridade }\end{array}$ & $\begin{array}{l}\text { A criança deve aprender as habilidades da } \\
\text { cultura ou enfrentar sentimentos de } \\
\text { incompetência. }\end{array}$ \\
\hline $\begin{array}{r}\text { Puberdade ao } \\
\text { adulto jovem }\end{array}$ & $\begin{array}{l}\text { Identidade versus } \\
\text { Confusão de Papéis }\end{array}$ & $\begin{array}{l}\text { O adolescente deve determinar seu próprio } \\
\text { senso de eu ("quem sou eu?") ou } \\
\text { experimentar uma confusão de papéis. }\end{array}$ \\
\hline Adulto jovem & $\begin{array}{l}\text { Intimidade versus } \\
\text { Isolamento }\end{array}$ & $\begin{array}{l}\text { A pessoa procura estabelecer compromissos } \\
\text { com os outros; se não for bem-sucedida, } \\
\text { poderá sofrer isolamento e auto absorção }\end{array}$ \\
\hline $\begin{array}{c}\text { Vida adulta } \\
\text { intermediária }\end{array}$ & $\begin{array}{c}\text { Generatividade } \\
\text { versus Estagnação }\end{array}$ & $\begin{array}{l}\mathrm{O} \text { adulto maduro preocupa-se } \\
\text { estabelecer e orientar a próxima geração, ou } \\
\text { então sente um empobrecimento pessoal. }\end{array}$ \\
\hline $\begin{array}{l}\text { Vida adulta } \\
\text { tardia }\end{array}$ & $\begin{array}{l}\text { Integridade do Ego } \\
\text { versus } \text { Desespero }\end{array}$ & $\begin{array}{l}\text { O idoso alcança a aceitação da própria vida, } \\
\text { o que favorece a aceitação da morte, ou } \\
\text { então se desespera com a incapacidade de } \\
\text { reviver a vida. }\end{array}$ \\
\hline
\end{tabular}

Fonte: Adaptado de Leite et al. (2019). 
(compreendida dos 6 anos à puberdade), caracteriza-se como a fase em que a criança se percebe como pessoa trabalhadora, capaz de produzir e se sente competente.

Durante o quarto estágio do processo epigenético, a criança precisa controlar sua imaginação exuberante e dedicar-se à educação formal. Ela desenvolve um senso de aplicação e aprende as recompensas da perseverança e da diligência. O interesse por brinquedos e pelo brincar é gradualmente superado por um interesse por situações produtivas e pelos implementos e instrumentos usados para trabalhar. O perigo desse estágio é a criança desenvolver um senso de inferioridade se for (ou fizerem com que se sinta) incapaz de dominar as tarefas que inicia ou que lhe são dadas pelos professores e pelos pais. (HALL et al., 2007, p. 172).

Conforme citado por Erikson (1968, apud PAPALIA et al., 2001), nota-se que, no período supracitado, a criança amplia sua iniciativa, capacidade de pensar e decidir como agir, atrelado ao desenvolvimento do eu, da compreensão das emoções, personalidade e relações sociais, porém, quando não é favorecido, pode florescer o sentimento culpa, incapacidade e inferioridade. Assim, diante das peculiaridades dessa fase, será abordada a colaboração dos contos de fadas para o desenvolvimento psicossocial infantil

\section{Contribuição dos Contos de Fadas para o Desenvolvimento Psicossocial Infantil}

Neste tópico, explora-se a contribuição dos contos de fadas para o desenvolvimento psicossocial infantil nos seguintes aspectos: desenvolvimento do eu, relações sociais, personalidade, compreensão das emoções e resolução dos conflitos relacionados ao sentimento de culpa, incapacidade e inferioridade.

Falconi et al. (2015) afirmam que os contos de fadas auxiliam no processo do desenvolvimento do eu e das relações sociais, pois oportunizam que as crianças criem seu próprio mundo com sonhos e fantasias, contribuindo para o autoconhecimento e reconhecimento do ambiente em que estão inseridas.

É através de uma história e de personagens que se podem conhecer outros lugares e outros jeitos de agir e ser, assim irá enriquecer a identidade da criança, pois ela irá experimentar outras formas de ser e de pensar, deixando fluir seu imaginário e levando-a ter curiosidade, que logo é respondida no decorrer de um conto, possibilitando a ampliação do desenvolvimento e de suas concepções de papéis sociais. (FALCONI et al., 2015, p. 103).

Bettelheim (2002) reitera que ouvir história é fundamental para o desenvolvimento da identidade da criança, pois possibilita ensaiar seus papéis na comunidade e ajustar acontecimentos à sua realidade. Assim, propicia que as crianças aprendam mais sobre as dificuldades familiares e as possibilidades de solução para seus problemas em uma sociedade.

Ainda segundo este autor, os contos de fadas são importantes no processo de compreensão das emoções e da personalidade. Assim, relata que este diverte e estimula a imaginação da criança ao mesmo tempo em que favorece o desenvolvimento da sua personalidade e percepção das emoções. (BETTELHEIM, 2002).

Para Ressurreição (2005), os contos falam de emoções comumente presentes na infância, como inveja, medo, tristeza, raiva, ciúmes e vergonha, proporcionando a descoberta, vivência e compreensão desses sentimentos por meio dos personagens.

Em relação à formação da personalidade, a contribuição acontece através da assimilação dos conteúdos das histórias, visto que os contos de fadas atuam de maneira consoante ao caminho pelo qual uma criança pensa e experimenta o mundo. Desta forma, eles contribuem muito na formação da personalidade. Ademais, todo conto de fadas possui uma mensagem significativa, um ensinamento, uma ideologia, indispensáveis na formação da personalidade. (BETTELHEIM, 2002; NASCIMENTO, 2011)

Cabral (2013) aponta, ainda, como aporte dos contos de fadas o desenvolvimento da autoestima, pois quando os heróis ultrapassam as barreiras, transmitem para a criança a possibilidade de vencer seus dilemas, amenizando o sentimento de culpa, incapacidade e inferioridade.

Outrossim, estimulam a confiança da criança, que passa a acreditar no seu potencial e que também pode vencer, fornecendo uma base de apoio para que ela se sinta fortalecida, sendo assim, são um recurso valioso na construção da autoestima. (BETTELHEIM, 2002).

Os contos de fadas funcionam como veículos infinitos de descobertas e de compreensão de mundo e de si mesmas, instigam a criança a vencer barreiras por meio do mundo mágico da imaginação. E através deles, ela vai se descobrindo e resolvendo seus problemas, dilemas, conflitos e afirmando conceitos conforme sua maturidade e raciocínio. (BARBOSA et al., 2019).

Diante disto, observa-se que a contribuição dessa literatura para o desenvolvimento psicossocial ocorre quando a criança a escuta e se identifica com o enredo e os personagens, passando a fazer parte da história, trazendo para a realidade aquilo que vivencia na fantasia $\mathrm{e}$, com isso, compreende melhor sua identidade, o meio em que está inserida, suas emoções, personalidade e seus conflitos

\section{Considerações Finais}

Reitera-se que antes do século XVII não havia histórias com linguagem adequada e que pudessem 
atender às particularidades da infância, visto que a literatura infantil desempenha um papel relevante no desenvolvimento psicossocial.

Evidencia-se que ao ouvirem histórias, as crianças conectam-se com seu mundo interno, possibilitando o autoconhecimento e identificação com a realidade exterior. Além disso, os contos de fadas propõem pontos de assimilação, assim, auxiliam as crianças a conceber estratégias para se posicionarem no mundo e compreender o que as rodeia. Assim, pode-se afirmar que essas narrações são um recurso muito importante para as crianças desenharem seu mapa imaginário, que promove o desenvolvimento do eu e indica seu lugar na família e no mundo.

Os contos de fadas fornecem significados e conceitos que poderão auxiliar na formação da personalidade, pois através da história contada a criança pode se identificar com um personagem ou história vivida, auxiliando assim no desenvolvimento de sua personalidade.

É relevante ressaltar, ainda, que os personagens dos contos exercem grande influência na compreensão das emoções, pois oferecem enredos que retratam sentimentos presentes na infância, como raiva, medo, alegria e tristeza, servindo de instrumento para interpretá-las.

Ademais, quando os heróis superam os obstáculos, promovem autoconfiança e passam a acreditar no seu potencial, contribuindo para a resolução dos conflitos e dilemas característicos da infância.

A partir das discussões teóricas apresentadas e da análise realizada, constata-se que essa literatura desempenha um papel relevante nos aspectos do desenvolvimento psicossocial abordados neste artigo, pois, pormeio dos seus enredos e personagens, as crianças delineiam experiências reais. Assim, ordenam melhor seu interior e atuam como veículos de descobertas de si mesmos, de compreensão de mundo e das emoções e de construção da personalidade, além de instigar a criança a vencer os conflitos.

Por fim, considera-se que este estudo foi de grande valia, visto que evidenciou que a inserção dos contos de fadas no mundo infantil contribui significativamente para o desenvolvimento, social e psicológico das crianças.

Assim, sugere-se, para trabalho futuro, um estudo de caso à luz da bibliografia aqui utilizada, ou novas pesquisas que oportunizem ampliar as teorias apresentadas, trazendo para este contexto teórico as experiências dos profissionais da Psicologia.

\section{Referências}

ARIÈS, Philippe. História social da infância e da família. Tradução: D. Flaksman. Rio de Janeiro: LCT, 1978.
AZEVEDO, Ricardo. Literatura infantil: origens, visões da infância e certos traços populares. Revista Presença Pedagógica. Belo Horizonte, Editora Dimensão, No 27 - mai/ jun 1999.

BARBOSA, Eliane Rodrigues; LIMA, Marilda de Souza. Contos de fadas na educação infantil: como forma de prazer e magia agregando valores éticos e morais. Revista Multidisciplinar do Nordeste Mineiro, vol. 2, 2019.

BETTELHEIM, Bruno. A psicanálise dos contos de fadas. $16^{\mathrm{a}}$ edição. Rio de Janeiro: Paz e Terra, 2002.

CABRAL, Tailor Alves. Conto de Fadas: uma ferramenta terapêutica. 2013. 50 f. Monografia (graduação em Psicologia) - Faculdade de Educação e Meio Ambiente, Ariquemes, 2013.

CAVALCANTI, Joana. Caminhos da literatura infantil e juvenil: dinâmicas e vivencias na ação pedagógica. São Paulo: Paulus, 2002.

DOHME, Vania D’Angelo. Técnicas de contar histórias: um guia para desenvolver as suas habilidades e obter sucesso na apresentação de uma história. Petrópolis: Editora Vozes, 2011

FALCONI, Isabela Mendes; FARAGO, Alessandra Corrêa. Contos de Fadas: origem e contribuições para o desenvolvimento da criança. Cadernos de Educação: Ensino e Sociedade, Bebedouro, p. 85-111, 2015.

HALL, Calvin S.; LINDZEY, Gardner.; CAMPBELL, John B. Teorias da personalidade. Tradução Maria Adriana Verissimo Veronese. Porto Alegre: Artmed, 2007.

KUPSTAS, Márcia. Sete faces do conto de fadas. $6^{\text {a }}$ edição. São Paulo. Moderna, 1993.

LEITE, Artur Alexandre de M.; SILVA, Marcos Leandro. Um estudo bibliográfico da Teoria Psicossocial de Erik Erikson: contribuições para a educação. Revista Debates em Educação, Vol. 11, nº. 23, Maceió, Jan./Abr. 2019.

NASCIMENTO, Mary Celina Barbosa do; LOPES, Telma Jannuzzi da Silva. O imaginário infantil: a importância dos contos de fadas no desenvolvimento da criança. X Congresso Nacional de Educação, I Seminário Internacional de Representações Sociais, Subjetividade e Educação. Pontifícia Universidade Católica do Paraná, Curitiba, p. 16425 - 16435, 2011

PAPALIA, Diana; OLDS, Sally Wendkos; FELDMAN, Ruth Duskin. O mundo da criança. 8. ${ }^{a}$ edição. Lisboa: McGraw-Hill, 2001.

PEREIRA, Veruska Oliveira Bonete; LEMOS, Moises Fernandes. A função terapêutica dos contos de fadas: sentimentos e conflitos humanos. Revista Perspectivas em Psicologia, Vol. 17, N. 2, Jul/Dez 2013, p. 102-114.

RESSURREIĈ̃̃O, Juliana Boeira da. A importância dos contos de fadas no desenvolvimento da imaginação. 2005. 34 f. Trabalho de Conclusão de Curso (Pós-graduação em Novas Abordagens em Língua Portuguesa e Literatura da Língua Portuguesa) - Centro Universitário Cenecista de Osório, Osório, 2005.

SCHNEIDER, Raquel Elisabete Finger; TOROSSIAN, Sandra Djambolakdijan. Contos de fadas: de sua origem à clínica contemporânea. Psicologia em Revista, Belo Horizonte, v. 15, n. 2, p. 132-148, ago. 2009. SIFUENTES, Thirza Reis; DESSEN, Maria Auxiliadora; OLIVEIRA, Maria Cláudia Santos Lopes de. Desenvolvimento Humano: Desafios para a Compreensão das Trajetórias Probabilísticas. Revista Psicologia: Teoria e Pesquisa, Vol. 23 n. 4, p. 379-386, Out-Dez, 2007.

SILVA, Fabrícia Pedro da. Vivenciando os contos de fada na educação infantil. 2013. 48f. Monografia (graduação em Pedagogia) - Universidade Federal da Paraíba, Centro de Educação, João Pessoa, 2013 